\title{
PERANCANGAN KARAKTER TOKOH BAMBANG EKALAYA PADA FILM ANIMASI BAMBANG EKALAYA
}

\author{
Maya Ismadarati, Azhari Amri \\ Program Studi Desain Komunikasi Visual \\ Fakultas Bahasa dan Seni, Universitas Indraprasta PGRI \\ Jl. Nangka No. 58 C, Tanjung Barat, Jakarta 12530, Indonesia \\ Mayadara625@gmail.com
}

\begin{abstract}
Abstrak
Bambang Ekalaya merupakan tokoh cerita bagian dari Mahabharata yang belum popular. Bambang Ekalaya adalah seorang pemuda yang gagah dan tidak pernah menyerah dalam menuntut ilmu meski telah ditolak oleh sang guru. Kisah Bambang Ekalaya dalam pewayangan penuh dengan pesan moral yang cocok untuk generasi muda agar tidak pantang menyerah dalam menuntut ilmu. Penelitian ini dilakukan menggunakan metode kualitatif untuk menciptakan sebuah film animasi yang memiliki karakter, sehingga perlu kiranya merancang sebuah tokoh utama yang memiliki sifat dan moral yang dapat ditiru oleh penontonya. Sehingga generasi muda kedepannya akan lebih tertarik dan memiliki minat untuk melestarikan pewayangan Indonesia.
\end{abstract}

Kata Kunci: Cerita pewayangan, Bambang Ekalaya, Pesan Moral

\begin{abstract}
Bambang Ekalaya is a vigure from the story of Mahabarata that'snot yet popular. He is a young and manly man who's never give up to pusuing his study eventough his teacher rejects him. The story of Bambang Ekalaya in the world of wayang puppetery is full of moral values that suitable for young generation to be inspired and not giving up on their study and pursuing knowledge. This research is using the qualitative method of analysis to create a vigure that have character. Thus it's needed to create a character that has a character that has a characteristic and values that could become an example for it's audience. Therefore the future generation will be more interested to study the Indonesian history.
\end{abstract}

Keywords:Puppet story, Bambang Ekalaya, moral message

\section{PENDAHULUAN}

Wayang termasuk seni dekoratif yang merupakan ekspresi dari kebudayaan nasional. Di samping itu, wayang merupakan pendidikan, media informasi, dan media hiburan. Ditinjau dari segi isinya, wayang merupakan media pendidikan karena banyak memberikan ajaran-ajaran kepada manusia. Baik manusia sebagai individu maupun manusia sebagai anggota masyarakt. Wayang bermanfaat dalam pendidikan budi pekerti, oleh karena itu wayang perlu dilestarikan, dikembangkan, khususnya wayang kulit Purwa (Soekatno, 2009: 1).

Banyak tokoh-tokoh pewayangan Purwa selain pandawa lima dan seratus Kurawa di cerita Mahabarata yang tidak populer di masyarakat, contohnya adalah cerita tokoh Bambang Ekalaya. Padahal setiap cerita dari tokoh wayang mempunyai filosofi yang sangat bagus. Pada cerita kisah 
hidup Bambang Ekalaya ini mengajarkan bahwa jangan cepat untuk putus asa dan pantang menyerah dalam menuntut ilmu.

Namun munculnya kecanggihan teknologi mulai menggeser budaya lokal. Wayang atau dunia pewayangan pastilah akan lenyap manakala masyarakat sudah tidak menyukainya lagi dan kesukaan atau kegemaran masyarakat itu pun akan selalu berubah dari waktu ke waktu. Oleh karena itu yang paling penting dalam upaya pelestarian wayang adalah mengusahakan agar masyarakat tetap menyenangi dan mencintai wayang (Sujamto, 1992: 81). Semakin sedikitnya peminat dan media yang menceritakan kisah wayang saat ini sangat dibutuhkan upaya untuk melestarikan dan mengangkat kembali cerita-cerita pewayangan kepada masyarakat saat ini agar tetap menyukai wayang.

Dalam upaya melestarikan budaya bangsa yaitu wayang salah satunya, haruslah diimbangi dengan perkembangan jaman dan teknologi. Saat ini banyak mahasiswa yang mengangkat tokoh pewayangan sebagai tugas akhirnya dalam upaya pelestarian wayang seperti salah satu karya dengan media motion comic karya Philipus Nicolaus Karamoy, Deny Tri Ardianto, S.Sn., dan Erandaru, ST, M.Sc.3. (2013) dalam jurnalnya yang berjudul "Perancangan Motion Comic Tokoh Pewayangan Bambang Ekalaya”. Mereka membuat karakter tokoh wayang Bambang Ekalaya untuk karya motion comic.

Seiring berkembangnya dunia perfilman, semakin banyak film yang diproduksi dengan corak yang berbeda-beda dan banyak film yang mengangkat cerita tentang legenda atau cerita rakyat. Film animasi pun mengalami perkembangan yang sangat pesat.

Peneliti pun membuat inovasi membuat karya film animasi dan memilih cerita pewayangan Bambang Ekalaya untuk dijadikan film animasi 2D, karena cerita Bambang Ekalaya mengandung ajaran atau pendidikan moral dan berisi tentang semangatnya menuntut ilmu. Kisah Bambang Ekalaya dikemas dalam bentuk cerita yang menarik, sehingga melalui pengungkapan cerita wayang Bambang Ekalaya dapat menyampaikan pesan moral pendidikan kepada anak-anak remaja untuk selalu bersemangat dalam menuntut ilmu.

\section{METODE PENELITIAN}

Pendekatan kualitatif dalam penelitian ini digunakan untuk mengumpulkan data literatur, observasi, dan wawancara, khususnya pemahaman tentang penciptaan karakter visual utusan budaya melalui elemen desain. Observasi dilakukan di Taman Mini Indonesia Indah Jakarta dalam festival dalang 2018, untuk mengamati jalan cerita pewayangan dengan mewawancarai Pak Margono sebagai seorang pengrajin wayang. Metode kepustakaan dilakukan dengan cara mengumpulkan melalui media-media online maupun cetak seperti koran, buku, jurnal yang membahas tentang pewayangan. Metode dokumentasi dengan mengumpulkan gambar, foto, arsip, film untuk menjadikan sebagai bukti valid.

\section{HASIL DAN PEMBAHASAN Sinopsis Bambang Ekalaya}

Tokoh pewayangan Bambang Ekalaya merupakan salah satu banyaknya tokoh-tokoh pewayangan selain Pandawa lima dan seratus Kurawa di cerita Mahabarata yang tidak populer di masyarakat. Nama Bambang Ekalaya adalah seorang pangeran kaum Nisada. Kaum Nisada adalah kaum yang paling rendah yaitu kaum pemburu, namun memiliki kemampuan yang setara dengan Arjuna dalam ilmu memanah. Bambang Ekalaya bertekat ingin menjadi pemanah terbaik di dunia, lalu ia pergi ke Hastina bermaksud berguru kepada Bhagawan Drona tetapi ditolak. Karena keinginannya yang kuat untuk menimba ilmu panah lebih jauh, menuntun dirinya untuk datang ke Hastina dan berguru langsung pada Drona. Namun niatnya ditolak, dikarenakan kemampuannya yang bisa menandingi Arjuna, dan keinginan Arjuna sebagai satu-satunya ksatria pemanah paling unggul di jagat raya, yang mendapat pengajaran langsung dari sang guru. Ini menggambarkan sisi negatif dari Drona, serta menunjukkan sikap pilih kasih Drona kepada murid-muridnya, dimana Drona sangat menyayangi Arjuna melebihi murid-muridnya yang lain. Bambang Ekalaya pun belajar di bawah bayangan patung sang Guru. Penolakan sang guru tidak menghalangi niatnya untuk memperdalam ilmu keprajuritan, ia kemudian kembali masuk ke 
hutan dan mulai belajar sendiri dan membuat patung Drona serta memujanya dan menghormati sebagai seorang murid yang sedang menimba ilmu pada sang guru. Berkat kegigihannya dalam berlatih, Bambang Ekalaya menjadi seorang prajurit yang gagah dan cakap.

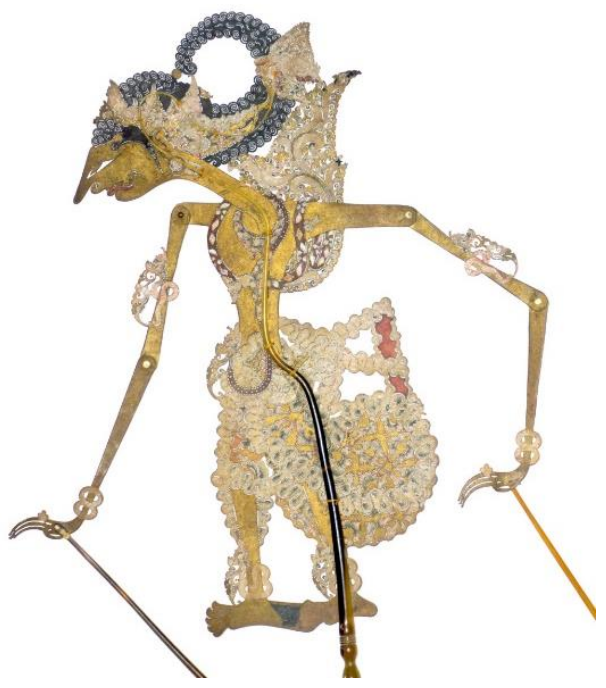

Gambar 1 Visualisasi Ekalaya dalam wayang purwa Sumber : Sumari 2018

Soekatno (2010: 179), menjelaskan bahwa dalam pewayangan Jawa, Ekalawya atau Ekalaya (dalam cerita pedalangan dikenal pula dengan nama "Palgunadi") adalah Raja negara Paranggelung. Dalam bahasa sansekerta, kata Ekalawya secara harfiah berarti "ia yang memusatkan pikirannya kepada suatu ilmu/mata pelajaran". Sesuai dengan arti namanya, Ekalawya adalah seorang kesatria yang memusatkan perhatiannya kepada ilmu memanah.

Ekalaya seorang raja kesatria, yang selalu mendalami olah keprajuritan dan menekuni ilmu peperangan. Ia sangat sakti dan sangat mahir mempergunakan senjata panah. Ia juga mempunyai cincin pusaka bernama Mustika Ampal yang menyatu dengan ibu jari tangan kanannya. Adapun watak yang dimiliki Ekalaya adalah seorang yang berwatak jujur, setia, tekun dan tabah. Ekalaya seorang yang gigih dalam menuntut ilmu (Akbar Kaelola, 2010: 179).

Setiap cerita dari tokoh wayang mempunyai filosofi yang sangat bagus. Pada cerita kisah hidup Bambang Ekalaya ini mengajarkan bahwa jangan cepat untuk putus asa dan pantang menyerah dalam menuntut ilmu. Dalam pewayangan, Bambang Ekalaya adalah tokoh yang sangat gigih dalam menuntut ilmu dan dijadikan sebagai teladan bagi kehidupan manusia. Bambang Ekalaya merupakan tokoh dalam pewayangan yang memiliki perjalanan hidup yang penuh dengan ketulusan sebagai murid kepada gurunya.

Alasan peneliti memilih Bambang Ekalaya karena tokoh ini memiliki ajaran atau pendidikan moral dan berisi tentang semangatnya menuntut ilmu. Kisah Bambang Ekalaya dikemas dalam bentuk cerita yang menarik, sehingga melalui pengungkapan cerita wayang Bambang Ekalaya dapat menyampaikan pesan moral pendidikan kepada anak-anak remaja untuk selalu bersemangat dalam menuntut ilmu. Sehingga kiranya menjadikan Bambang Ekalaya menjadi tokoh utama adalah pilihan yang tepat.

\section{Proses Perancangan Karakter}

Segmentasi

Upaya untuk melestarikan warisan budaya wayang harus diimbangi dengan perkembangan jaman dan teknologi. Agar cerita wayang ini tetap menarik di generasi muda Indonesia, maka dibuatlah sebuah film animasi dengan bahasa Indonesia yang baku sebagai media pelestarian cerita wayang. Melihat keseharian generasi muda Indonesia di zaman modern ini yang suka online, menonton anime, film barat dan sebagainya maka perancangan pembuatan karakter 
Bambang Ekalaya dalam film animasi Bambang Ekalaya merupakan media yang tepat. Tentu saja dalam film animasi cerita tokoh pewayangan Bambang Ekalaya ini juga mengandung filosofi dan pesan yang ingin disampaikan pada generasi muda Indonesia.

Target audiens dari karya ini lebih difokuskan kepada generasi muda Indonesia dengan jarak umur antara 12-20 tahun. Umur 12-20 adalah umur perubahan dari remaja ke dewasa muda, pada umur ini seringkali mengalami kondisi labil dalam hidup mereka. Oleh karena itu cerita inspiratif ini sangat cocok bagi umur tersebut untuk menginspirasi mereka.

\section{Proses Karakter}

Dalam proses pengolahan objek akan terjadi suatu perubahan wujud sesuai dengan selera yang dimiliki, perubahan wujud tersebut diantaranya adalah stilasi, distorsi, transformasi, dan disformasi (Sari, 2015: 15).

Desain karakter dapat dibangun melalui elemen desain dari garis, bentuk, tekstur, dan warna. Elemen garis dan bentuk dapat menyajikan kepribadian, emosi, ekspresi, dan mewakili identitas seperti jenis kelamin, kelas sosial, dan nilai-nilai budaya melalui ilustrasi dari pakaiannya. Berdasarkan tinjauan literatur yang mendasari penciptaan karakter visual, maka tujuan dari penelitian ini adalah untuk memberikan referensi, inspirasi, serta mendorong pengembangan produk kreatif digital yang mempromosikan nilai-nilai budaya lokal, termasuk melalui perancangan visual karakter tokoh Bambang Ekalaya dalam film animasi Bambang Ekalaya.

Akbar, T., Pratama, D., dan Wardani, W, G, W,. (2018) menjelaskan, "The process of designing characters are based on the historical figure, the proportion of the human body, and combines it with those seen on statues, sculptures, or other artefacts that can help in the design process The characterizations of characters design in visual novels are built through the physical appearance of body proportions (to reflect certain characters and personalities of a high, short, large, or small body shape)".

Menurut Akbar, T., Pratama, D., dan Wardani, W, G, W,. (2017: 207) dalam penelitiannya yang berjudul "Designing Visual Character Of Raden Wijaya As Historical Figure In Visual Novel", menjelaskan "visual characters are designed through line elements, shapes, textures, and colors. Messages designed through visual characters can include cultural ideas. Therefore, the visual character of local cultural values can potentially be a symbolic product that carries a cultural message".

Karakter Bambang Ekalaya dalam film animasi dirancang oleh peneliti dibuat dengan teknik transformasi dari wayang kulit Purwa Bambang Ekalaya yang diterapkan pada tokoh Bambang Ekalaya dan dengan melihat karakter yang sudah pernah dibuat sebelumnya dengan media komik motion sebagai tinjauan objek dan studi refrensi.

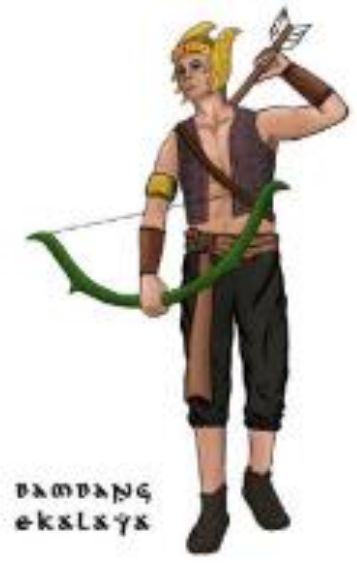

Gambar 2 Karakter Bambang Ekalaya dari Komik Motion karya Tugas Akhir Universitas Kristen Petra Surabaya, Philipus Nicolaus Karamoy 
Pada komik motion ini, ilustrasi pada karakter masih kurang dalam proporsinya. Pendalaman bentuk dari masing-masing karakter masih kurang menggambarkan tokoh yang digambarkan. Untuk mengenalkan suatu tokoh, perancang haruslah meneliti terlebih dahulu secara mendalam karakter-karakter yang sudah ada dari kemiripan bentuk fisik maupun ciri khas yang dapat ditonjolkan dari tiap tokoh tersebut. Hal tersebut agar mempermudah audiens dapat mengenali dengan tokoh-tokoh dari komik motion tersebut, walaupun di berbeda media seperti contohnya media wayang kulit, atau wayang orang (Saptodewo 2015: 153).

Dalam proses kreativitas dalam berkesenian memberikan kebebasan penapsiran bagi siapa saja yang ingin mewujudkan suatu ide dalam karya. Penerapan ide ditentukan oleh konsep karya atas nilai-nilai yang terkandung di dalamnya. Nilai tersebut diterapkan ke dalam bentuk karya seni, sehingga judul, tema, dan strukturnya dapat memberikan kejelasan Saptodewo (2014: 107).

Karakter yang dipakai dalam pembentukan film animasi Bambang Ekalaya yaitu akan mengalami perubahan bentuk dari karakter wayang kulit menjadi bentuk orang dengan adanya engsel wayang sebagai ciri khas dari tokoh pewayangan itu sendiri. Perancangan karakter tokoh Bambang Ekalaya tetap menerapkan beberapa bentuk organ tubuh maupun atribut wayang kulit Surakarta. Hal tersebut dilakukan untuk mempertahankan karakteristik seni budaya wayang kulit Indonesia.

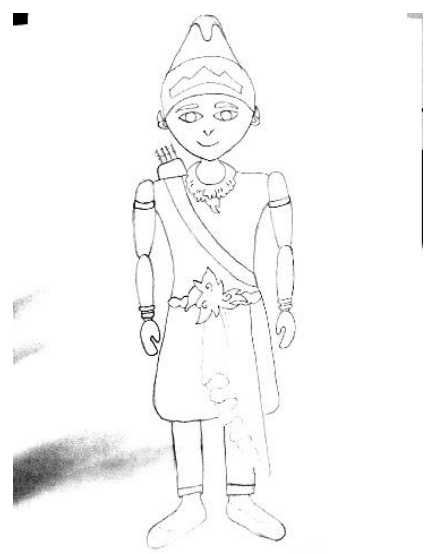

Gambar 3 Alternatif 1 perancangan karakter Bambang Ekalaya Sumber : Dokumen Pribadi

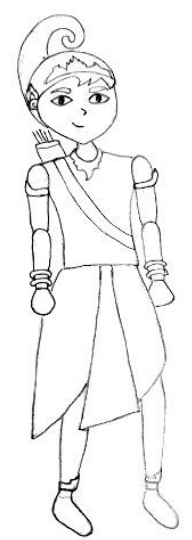

Gambar 4 Alternatif 2 perancangan karakter Bambang Ekalaya Sumber : Dokumen Pribadi 


\section{Hasil Perancangan}

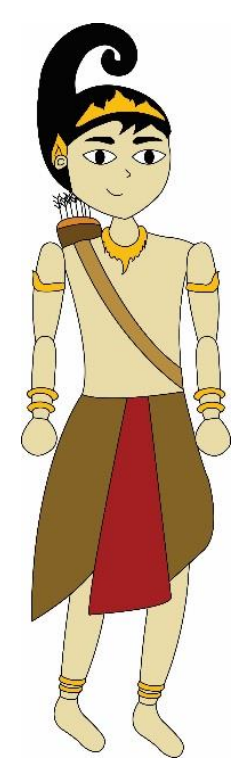

Gambar 5 Hasil akhir perancangan karakter Bambang Ekalaya Sumber : Dokumen Pribadi

Sesuai dengan data dan hasil penelitian yang didapat, serta mengacu kepada teori yang ada. Terciptalah sebuah rancangan karakter Bambang Ekalaya sebagai tokoh utama dalam film animasi Bambang Ekalaya. Kesan yang tercipta adalah karakter dengan sifat gagah, berani, tekun dan memiliki jiwa kesatria.

\section{SIMPULAN}

Perancangan karakter tokoh Bambang Ekalaya ini cukup efektif untuk menceritakan cerita wayang, namun memang berbeda dengan cara penyampaian oleh pertunjukan tradisional. Pertunjukan tradisional mengandung banyak sekali nilai budaya seperti cara dalang menyampaikan cerita, tutur kata dan bahasa, gerak-gerik tokoh pewayangan yang khas. Di dalam perancangan karakter ini hal-hal tersebut memang tidak dapat terlihat, namun makna cerita tetap bisa didapatkan dan nilai-nilai budaya masih tetap di pertahankan melalui perancangan karakter ini.

Berdasarkan tinjauan literatur yang mendasari penciptaan karakter visual, maka tujuan dari penelitian ini adalah untuk memberikan referensi, inspirasi, serta mendorong pengembangan produk kreatif digital yang mempromosikan nilai-nilai budaya lokal, termasuk melalui perancangan visual karakter tokoh Bambang Ekalaya dalam film animasi Bambang Ekalaya.

Karya ini dapat dengan mudah dikenal dan dilihat oleh generasi muda karena menggunakan media elektronik dan internet. Dengan demikian, diharapkan kisah cerita pewayangan Bambang Ekalaya dapat memberikan inspirasi dalam menuntut ilmu dan semangat kepada anak-anak remaja sekarang dan dapat terus diturunkan ke generasi selanjutnya.

\section{DAFTAR PUSTAKA}

Hardjowirogo. (1989). Sejarah Wayang Purwa. Jakarta: Balai Pustaka.

Kaelola, A. (2010). Mengenal Tokoh Wayang Mahabharata. Jakarta: Cakrawala.

Soekatno, B, A. (2009). Mengenal Wayang Kulit Purwa. Demak: Aneka Ilmu.

Sujamto. (1992). Wayang \& Budaya Jawa. Semarang: Dahara Prize. 
Pratama, D., Wardani, W. G. W., \& Akbar, T. (2017). Designing visual character of Raden Wijaya as historical figure in visual novel. International Journal Of Scientific \& Technology Research, 6(11), 207-210.

Pratama, D., Wardani, W. G. W., \& Akbar, T. (2018). Designing Visual Novel Characters of Gajah Mada and Tribhuwana Tunggadewi As Representation of History Figures. Humanus, 17(1), 84-96.

Karamoy, P. N., Ardianto, D. T., \& Erandaru, E. (2013). Perancangan Motion Comic Tokoh Pewayangan Bambang Ekalaya. Jurnal DKV Adiwarna, 1(2), 7.

Saptodewo, F. (2019). Perancangan Visualisasi Tokoh Wayang Bambang Tetuka. Jurnal Desain, 1(02), 102-109.

Saptodewo, F. (2016). Mempopulerkan Cerita Pewayangan Di Kalangan Generasi Muda Melalui Motion Comic. Jurnal Desain, 2(03), 145-156.

Sari, K. (2015). Perancangan Animasi Karakter Drupadi Dalam Pewayangan Jawa Sebagai Sosok Perempuan Tegar dan Setia. (skripsi). Universitas Indraprasta PGRI, Jakarta. 